Analytical Methods

\title{
Development of a rapid and simple voltammetric method to determine total antioxidative capacity of edible oils
}

\author{
Rubin Gulaboski ${ }^{\mathrm{a}, \mathrm{b}, *}$, Valentin Mirčeski ${ }^{\mathrm{a}, \mathrm{b}, \mathrm{c}}$, Saša Mitrev ${ }^{\mathrm{a}, \mathrm{b}, *}$ \\ a Department of Chemistry, Faculty of Agriculture, University “Goce Delčev” - Štip, Macedonia \\ b Department of Plant and Environment Protection, Faculty of Agriculture, University "Goce Delčev" - Štip, Macedonia \\ ${ }^{\mathrm{c}}$ Department of Chemistry, Faculty of Natural Sciences and Mathematics, "Ss Cyril and Methodius" University, Skopje, Macedonia
}

\section{A R T I C L E I N F O}

\section{Article history:}

Received 21 January 2012

Received in revised form 19 September 2012

Accepted 15 October 2012

Available online 8 November 2012

\section{Keywords:}

Reactive oxygen species

Antioxidants

Edible oils

Voltammetry

ABTS

Electron paramagnetic resonance

\begin{abstract}
A B S T R A C T
In this work we report on a new, rapid and simple voltammetric method to determine the total antioxidant capacity (TAC) of the edible oils. The method explores the ABTS radical (2,2'-azinobis(3-ethylbenzothiazoline-6-sulphonic acid)) assay as a redox probe and it relays on measuring catalytic voltammetric currents. The electrocatalysis comprises redox regeneration of the electrochemically created $\mathrm{ABTS}^{+} \mathrm{rad}^{-}$ ical either by Trolox (6-hydroxy-2,5,7,8-tetramethychroman-2-carboxylic acid) or by antioxidants present in studied oils. The detection limit of the method is determined to be $0.5 \mathrm{mg} / \mathrm{L}$ of Trolox equivalent, being a slightly lower than the corresponding UV-VIS spectrophotometric method. Applying the proposed voltammetric method the total antioxidant capacity of three types of commercially available cold-pressed edible oils are determined, and the results are found to be in a very good agreement with those obtained by UV-VIS spectrophotometry. The reported voltammetric method is cheap, rapid and simple, and it can be used as a sustainable alternative to the UV-VIS methods for the determination of total antioxidant capacitance of oils and other liquid lipophilic nutrients. Potent antioxidant capacity of studied oils was also confirmed by electron paramagnetic resonance spectroscopy of superoxide anion produced by macrophages.
\end{abstract}

(c) 2012 Elsevier Ltd. All rights reserved.

\section{Introduction}

It is widely recognised that the curbing of many diseases (Aruoma, 1998; Belitz \& Grosch, 1999; Bogeski, Kappl, Kummerow, Gulaboski \& Hoth, 2011; Cadenas \& Davies, 2000; Droge, 2002; Halliwell \& Gutteridge, 2002; Stanner, Hughes, Kelly, \& Buttriss, 2004 ) is directly linked to consumption of bioactive compounds such as vitamins $\mathrm{A}, \mathrm{D}, \mathrm{K}$ and $\mathrm{E}$, lipoic acid, and many polyphenolic derivatives as hydroquinones and flavonoids (Beardsell, Francis, \& Ridley, 2002; Manach, Scalbert, Morand, \& Jimenez, 2004; Novak, Seruga, \& Komorsky-Lovric, 2009, 2010; Visioli, Bogani, Grande, \& Galli, 2004; Yanishlieva-Maslarova \& Heinonen, 2001; Yu, Zhou, \& Parry, 2005). Cold-pressed edible vegetable oils are rich in a variety of lipophilic vitamins and polyphenols (Beardsell et al., 2002; Belitz \& Grosch, 1999; Manach et al., 2004; Visioli et al., 2004; Yanishlieva-Maslarova \& Heinonen, 2001; Yu et al., 2005). Total antioxidant capacity (TAC) of vegetable oils is most commonly assessed using the Trolox-ABTS assay (Re, Pellegrini, Proteggente, Pannala, \& Yang, 1999) because of its simplicity, but UV-VIS spectrophotometry, based on the same assay (Apak, Guclu, Demirata,

\footnotetext{
* Corresponding authors.

E-mail addresses: rubin.gulaboski@ugd.edu.mk (R. Gulaboski), sasa.mitrev@ugd. edu.mk (S. Mitrev).
}

Ozyurek, \& Celik, 2007; Gunstone \& Harwood, 2007; Re et al., 1999; Visioli et al., 2004; Yu et al., 2005), is also used. The Trolox Equivalent Antioxidant Capacity (TEAC) is often used for vegetables, fruits and other food products, coupled with UV-VIS spectrophotometry (Gunstone \& Harwood, 2007). Its capacity to measure activity of lipophilic as well as hydrophilic antioxidants makes it an assay of choice for routine determination of the TAC (Gunstone \& Harwood, 2007). In this work we describe a new electrochemical method that allows an easy and accurate determination of the total antioxidant capacity of oils. The proposed method relies on the socalled electrocatalytic mechanism in voltammetry, which comprises a chemical regeneration of ABTS radical in a reaction with Trolox or with the antioxidants that are present in the oils. The method is fast and simple, and it can be seen as a viable alternative for the UV-VIS methodology for the total antioxidant capacity determination.

\section{Materials and methods}

All chemicals were products of Sigma (Germany) having 99\% or higher purity and were used as received. All solutions were prepared by dissolution in ethanol. The oils used were obtained by cold-pressing procedure applied to sunflower, pumpkin and oil-turnip seeds, and were products from "Agrofila" company from 
Stip, Macedonia. All cold-pressed oils are commercially available. As a test-sample for purposes of comparison, we used refined sunflower oil.

Cyclic voltammetry (CV) and square-wave voltammetry (SWV) were performed with an AUTOLAB potentiostat model PGSTAT $128 \mathrm{~N}$ (Eco Chemie, the Netherlands) in a conventional three-electrode set-up. The reference electrode was an $\mathrm{Ag} / \mathrm{AgCl}$ ( $3 \mathrm{~mol} / \mathrm{L} \mathrm{KCl}$ ), Platinum wire was used as a counter electrode, while the ultratrace glassy carbon (Metrohm, $3 \mathrm{~mm}$ in diameter) was exploited as a working electrode. The working electrode was cleaned by polishing with aluminium powder for $60 \mathrm{~s}$, followed by rinsing with ethanol, and drying on air. The UV-VIS spectra were recorded with Ultrospec spectrophotometer model 2110 pro over the region from 450 to $900 \mathrm{~nm}$.

The TEAC assay was prepared according to the method reported elsewhere (Re et al., 1999) for both spectroscopic and voltammetric experiments, in order to make the two methods directly comparable. A stable radical cation of $\mathrm{ABTS}^{+}$was created by mixing solutions of a $7 \mathrm{mmol} / \mathrm{L}$ of ABTS salt (2,2'-azinobis(3-ethylbenzothiazoline-6-sulphonic acid)) diammonium salt) and $2.45 \mathrm{mmol} / \mathrm{L}$ of potassium persulfate in a volume ratio of $1: 1$ in ethanol. The reaction mixture was kept in dark for $8 \mathrm{~h}$ at $20^{\circ} \mathrm{C}$. The mixture could be used up to $52 \mathrm{~h}$ after preparation. The working $\mathrm{ABTS}^{+}$radical solution was diluted with an appropriate amount of ethanol to get suitable voltammetric responses (or absorbance of the signal at $734 \mathrm{~nm}$ in UV-VIS experiments). $\mathrm{KCl}$ at concentration of $0.05 \mathrm{~mol} / \mathrm{L}$ was added to the ethanol solution to serve as a supporting electrolyte in voltammetric experiments. Microlitre amount of the coldpressed oils were added to the ABTS ${ }^{+}$working solution, and the reaction mixture was left to react for $2-3 \mathrm{~min}$ at room temperature. Subsequently, we recorded several consecutive voltammograms in order to assess the stability of the system and the reproducibility of obtained results. The reaction between ABTS $^{+}$ and Trolox (6-hydroxy-2,5,7,8-tetramethychroman-2-carboxylic acid) was used as a reference system. As a control, we ran UVVIS measurements in parallel to the voltammetric experiments. For each point presented, we recorded at least 10 consecutive voltammograms, and the average value was taken. The standard deviation of the measured currents was $0.125 \mu \mathrm{A}$. For the square-wave voltammetric experiments, a potential increment of $1 \mathrm{mV}$, frequency of $10 \mathrm{~Hz}$, and square-wave amplitude of $50 \mathrm{mV}$ were used.

The electron paramagnetic resonance (EPR) experiments were performed with the Bruker spectrometer (ESP300e) equipped with a TMH cavity, in which the flat cell was placed immediately after filling with the reaction solution. The reaction system consisted of $100 \mu \mathrm{L}$ of stimulated monocyte-derived macrophage $(300,000$ units $/ \mathrm{mL}$ ) cell culture solutions in which a spin trapper 5,5-dimethyl-1-pyrroline-N-oxide (DMPO) was added. The DMPO is a specific spin-trapper that is sensitive to the superoxide anions that are being created by the macrophages. The modulation amplitudes varied between $10 \mathrm{mG}$ and $0.2 \mathrm{G}$. The microwave power was $0.63 \mathrm{~mW}$. The EPR spectra were recorded with scan times of $50 \mathrm{~s}$.

All experiments were performed at room temperature.

\section{Results and discussion}

The TEAC assay commonly refers to the ability of a given compound to scavenge the $\mathrm{ABTS}^{+}{ }^{+}$radicals (Re et al., 1999). The main goal of the present work was to develop a fast and simple electrochemical method for assessing the TAC of edible cold-pressed oils. Although the basic voltammetric features of ABTS are discussed elsewhere (Buettner, 1993; Geletii, Balavoine, Efimov, \& Kulikova, 2002; Stenken \& Neta, 1982), to date no voltammetric method has been developed for determination of the TAC in edible oils by using the ABTS assay.

\subsection{Basic electrochemistry of ABTS}

Fig. 1A shows the cyclic voltammogram of ethanol ABTS solution containing $0.05 \mathrm{~mol} / \mathrm{L} \mathrm{KCl}$ as a supporting electrolyte. Under such conditions, ABTS features two quasireversible electrode processes with mid-peak potentials of $+0.230 \mathrm{~V}$ and $+0.520 \mathrm{~V}$, respectively. These are referred to the oxidation of ABTS to $\mathrm{ABTS}^{+}$(the peak "1" at $+0.230 \mathrm{~V}$ ), and to the oxidation of $\mathrm{ABTS}^{+}$to $\mathrm{ABTS}^{2+}$ (the second peak "2" at $+0.520 \mathrm{~V}$ ) (Buettner, 1993; Geletii et al., 2002; Stenken \& Neta, 1982). The redox reactions associated with the two voltammetric signals in Fig. 1A can be described by following reaction scheme:

$\mathrm{ABTS} \leftrightarrows \mathrm{ABTS}^{++}+\mathrm{e}^{-} \leftrightarrows \mathrm{ABTS}^{2+}+\mathrm{e}^{-}$

Note that after certain period of time (after 8-12 h from the preparation), the less positive potential peak diminishes significantly; the effect is attributed to the chemical conversion of ABTS to ABTS ${ }^{+}$ radical. While at lower scan rates one clearly observes two distinct processes, at higher scan rates the first redox process $\left(1-1^{\prime}\right)$ is not so obviously pronounced in cyclic voltammetry. The reason for this can be attributed to the slower kinetics of the first redox process (Stenken \& Neta, 1982). After period of $12 \mathrm{~h}$, successive potential scanning gives a stable cyclic voltammogram, which is a good indicator for the stability of the system (see Fig. 1B). The linear dependence of the peak current vs. the square-root of the applied scan rate reveals the mass transfer of ABTS to the working electrode occurs primarily via diffusion (see Fig. $1 \mathrm{C}$ and D). The ratio between the cathodic and anodic peak currents of the second voltammetric process (peak pair 2-2') measured by all scan rates is relatively constant, ranging between 0.97 and 1.02. Moreover, the peak-to-peak separation between the anodic and cathodic peaks of the voltammetric signal 2-2' reads $60 \mathrm{mV}$ (at $10 \mathrm{mV} / \mathrm{s}$ ), and it only slightly changes by increasing the scan rates. These results imply that the second voltammetric process is attributed with a high degree of electrochemical reversibility. This is a very good indicator for exploring this process for analytical applications. All results described in this section are consistent with the voltammetric features of ABTS described elsewhere (Buettner, 1993; Geletii et al., 2002; Stenken \& Neta, 1982).

\subsection{Electrochemistry of ABTS in the presence of trolox}

Addition of Trolox to the electrochemical cell containing ABTS caused changes in the features of the voltammograms. Concentrations of Trolox higher than $0.01 \mathrm{mmol} / \mathrm{L}$ led to a successive increase of the oxidation peak currents of the second voltammetric signal that was followed by a decrease in the backward (reduction) component (see Fig. 2A). The voltammogram in Fig. 2A featuring the lowest oxidative current component was recorded in the absence of Trolox. When Trolox is added in the cell, it easily undergoes chemical reaction with the $\mathrm{ABTS}^{2+}$, which is the product of the $\mathrm{ABTS}^{+}$electrode oxidation. Such homogeneous redox reaction causes regeneration of the electrochemical reactant $\left(\mathrm{ABTS}^{+}\right)$in the course of the voltammetric experiment, enabling $\mathrm{ABTS}^{++}$to be again re-oxidised at the electrode surface. This phenomenon is portrayed by the increase of the oxidation current component, and concomitant decrease of the backward (reduction) current component. As the concentration of Trolox increases, the oxidative voltammetric currents increase further, since more ABTS $^{+}$gets regenerated during the voltammetric experiment. These features are typical for the so-called electrocatalytic regenerative EC' (or ECat) redox mechanism that are well known in the literature (Gosser, 1994; Gulaboski, 2008; Mirceski, Komorsky-Lovric, \& Lovric, 2007; O'Dea, Osteryoung, \& Osteryoung, 1981; Osteryoung \& Osteryoung, 1985). In the present case, this EC' reaction mechanism can be described with the following scheme: 

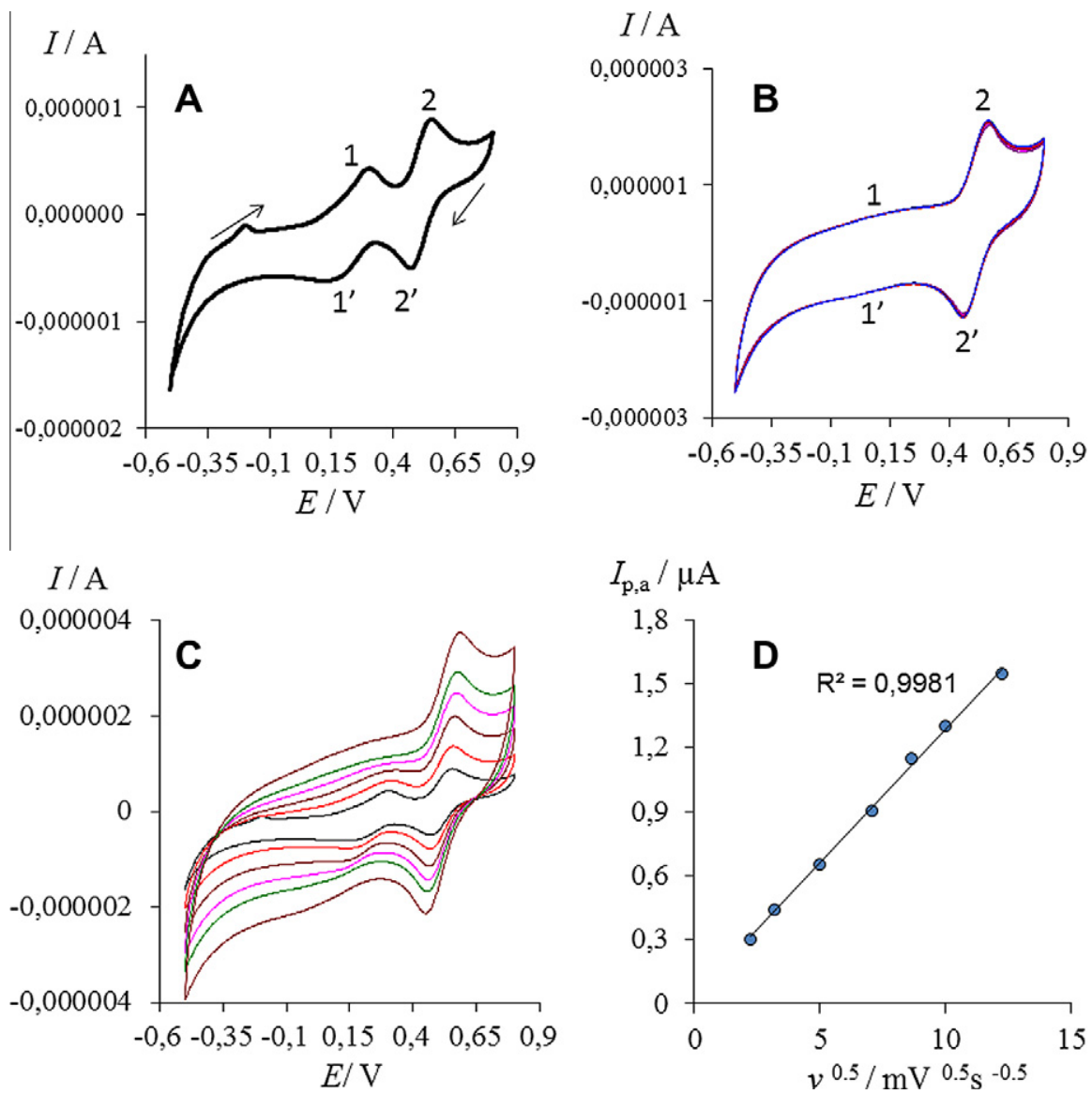

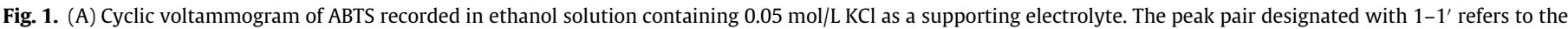

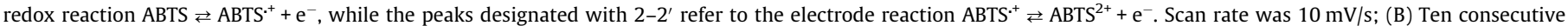

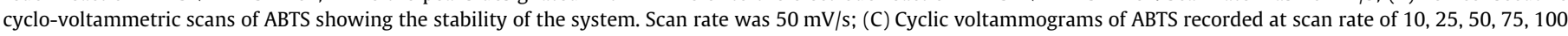

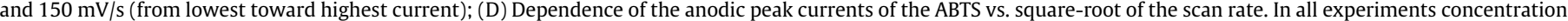
of ABTS was $0.05 \mathrm{mmol} / \mathrm{L}$.

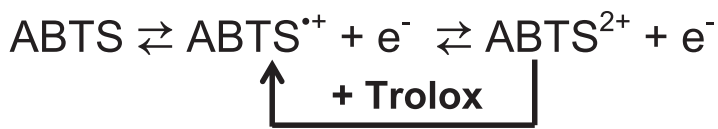

It is worth noting that Trolox itself gives a voltammetric signal that is portrayed as an irreversible redox process at potentials of about $+0.4 \mathrm{~V}$ (Geletii et al., 2002) (see Fig. 2A and B). In order to get more precise current measurements, we also exploited more sensitive square-wave voltammetry (SWV) as a working technique. Shown in Fig. 2B are SW voltammograms of ABTS recorded in the presence of various Trolox concentrations. The increase of the Trolox concentration causes linear increase of the peak currents of the square-wave voltammograms (see Fig. 2C). Note that in Fig. $2 C$ the dependence of $\Delta I_{\mathrm{p}}$ on the Trolox concentration is presented, where $\Delta I_{\mathrm{p}}$ is defined as the difference between the measured SW peak currents in the presence of corresponding Trolox concentrations $\left(I_{\mathrm{p}, \mathrm{x}}\right)$ and in the absence of Trolox $\left(I_{\mathrm{p}, 0}\right)$, i.e., $\Delta I_{\mathrm{p}}=$ $I_{\mathrm{p}, \mathrm{x}}-I_{\mathrm{p}, 0}$. The equation corresponding to the regression line in Fig. 2C reads: $\Delta I_{\mathrm{p}} / \mu A=5.845 \mathrm{c}($ Trolox $) / \mathrm{mmol} \mathrm{L}^{-1}+0.1774$. This equation was further explored for the determination of total antioxidative capacity of the cold-pressed edible oils.

\subsection{Electrochemistry of ABTS in the presence of cold-pressed edible oils}

Addition of microlitre amounts of cold-pressed edible oils in the electrochemical cell containing ABTS caused a successive increase of the SW net-peak currents, while the voltammograms gained features typical for the electrocatalytic regenerative mechanism (Fig. 3A) Gosser, 1994; Gulaboski, 2008; Mirceski et al., 2007; O'Dea et al., 1981; Osteryoung \& Osteryoung, 1985. Obviously, the antioxidants present in oils were having an effect similar to Trolox in the electrochemical experiments. The electrochemical reaction between the ABTS and the antioxidants present in the cold-pressed edible oils can be described with the following simplified reaction scheme:

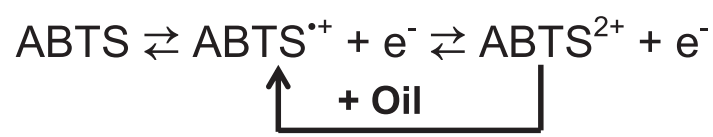

Shown in Fig. 3B is the dependence between the measured SW peak currents of ABTS vs. the volume ratio of edible oils added in the system. The good linearity between these two parameters indicates that the voltammetric method can be used for determination of total antioxidative capacity of the edible oils. The total content of the antioxidants in the oils has been determined by using the data presented in Fig. 3B and the calibration line obtained with Trolox (Fig. 2C). The results for the total antioxidant capacity (expressed in $\mathrm{mg} / \mathrm{L}$ Trolox equivalent) were determined to be 1.875 , 1.055 , and $0.435 \mathrm{mg} / \mathrm{L}$ for the cold-pressed sunflower oil, pumpkin oil, and turnip-oil, respectively. Note that we observed no catalytic currents when refined oil was added in the electrochemical cell 

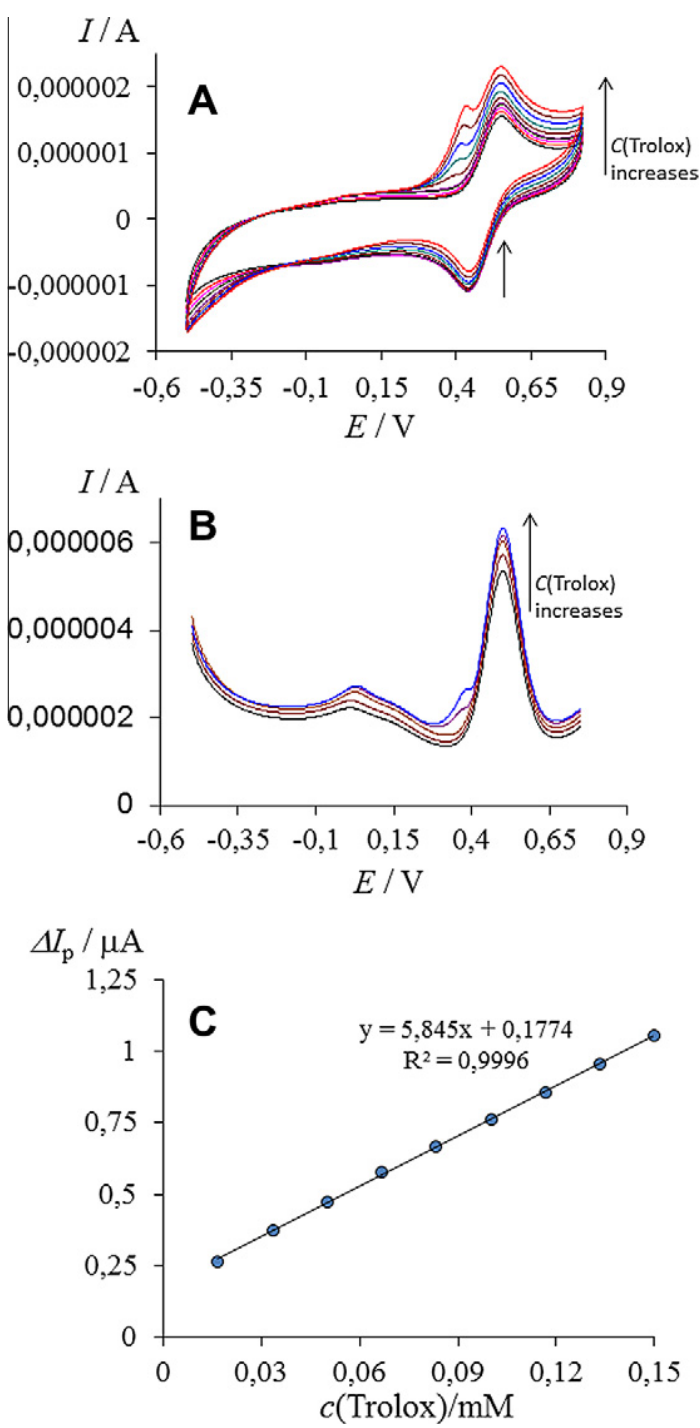

Fig. 2. Cyclic (A) and square-wave (B) voltammograms of ABTS, showing the effect of increasing Trolox concentration; (C) dependence of the $\Delta I_{\mathrm{p}}$ on the Trolox concentration. $\Delta I_{\mathrm{p}}$ is defined as difference between the measured SW peak currents in presence $\left(I_{\mathrm{p}, \mathrm{x}}\right)$ and in absence of Trolox $\left(I_{\mathrm{p}, 0}\right)$, i.e. $\Delta I_{\mathrm{p}}=I_{\mathrm{p}, \mathrm{x}}-I_{\mathrm{p}, 0}$. Other conditions are the same as in Fig. 1.

containing ABTS (see Fig. 3C). This indicates that significant amounts antioxidants are lost during the refining process of edible oils.

In order to prove the reliability of the established voltammetric methodology, we ran UV-VIS spectrophotometric measurements in parallel with the conventional Trolox-ABTS method. One example of the effect of Trolox and sunflower cold-pressed edible oil to the absorption band of ABTS assay is given in Fig. 4A and B, respectively. In both cases, a complete disappearance of the absorption band for ABTS at about $740 \mathrm{~nm}$, is due to the quenching the ABTS ${ }^{+}$ radical by Trolox or by the antioxidants present in the cold-pressed edible oils. The recovery tests made on all oil samples with the voltammetric techniques used ranged between $98.5 \%$ and $102.5 \%$. The discrepancies between the results for the total antioxidant capacity of cold-pressed edible oils found with UV-VIS and the proposed voltammetric method were in the range $\pm 3.2 \%$. This fact can serve as a qualitative indicator for the suitability and reliability of the established voltammetric method for determination of the total antioxidant capacity of edible oils.
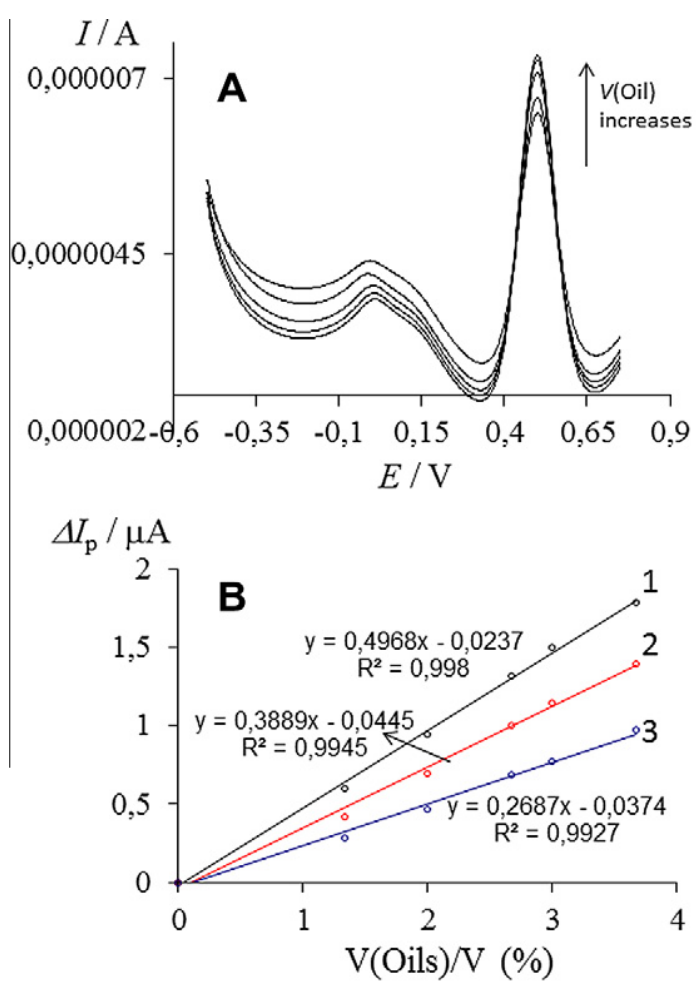

$I / \mathrm{A}$

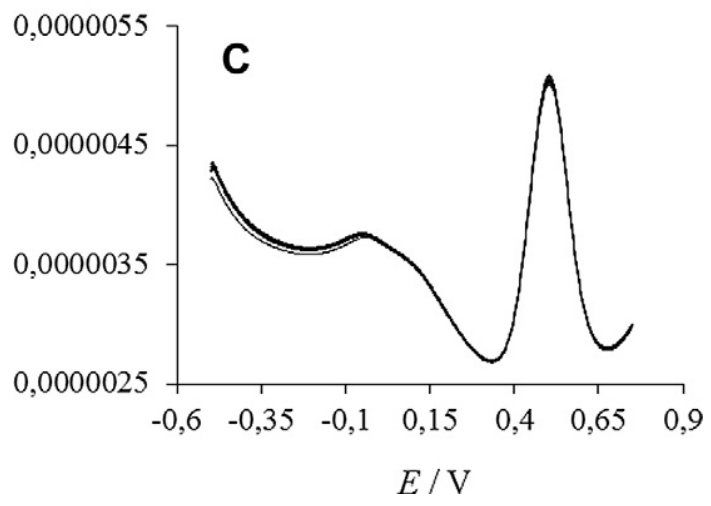

Fig. 3. (A) Square-wave voltammograms of ABTS showing the effect of increasing cold-pressed oil volume parts; (B) dependence of the $\Delta I_{\mathrm{p}}$ on the volume parts of cold-pressed sunflower (1), pumpkin (2) and turnip (3) edible oils; (C) refined edible oil shows no effect to the ABTS voltammograms. The volume part of the refined oil was increased up to $10 \%(\mathrm{v} / \mathrm{v})$. Other conditions are the same as in Fig. 1.

\subsection{Electron paramagnetic resonance experiments with macrophages in presence of edible oils}

In order to demonstrate the antioxidative effect of the studied cold-pressed edible oils to the living cells, we examined behaviour of macrophages that were stimulated to produce superoxide radicals. For this purpose, we ran electron paramagnetic resonance (EPR) experiments. By using an EPR set-up with DMPO as a spin trapper sensitive to superoxide anion radicals, we could observe the effect of the cold-pressed edible oils to the quenching of superoxide radical anions (see Fig. 5). From the curves presented in Fig. 5 we can see that even very small amounts $(1 \% \mathrm{v} / \mathrm{v})$ of cold-pressed edible oils can reduce significantly the content of the superoxide radicals created by the macrophages. The rate of the EPR signals decrease corresponds to the TAC of edible oils used. These EPRmacrophage experiments show how big is the potential of the cold-pressed edible oils as radical scavengers in the living cells. 

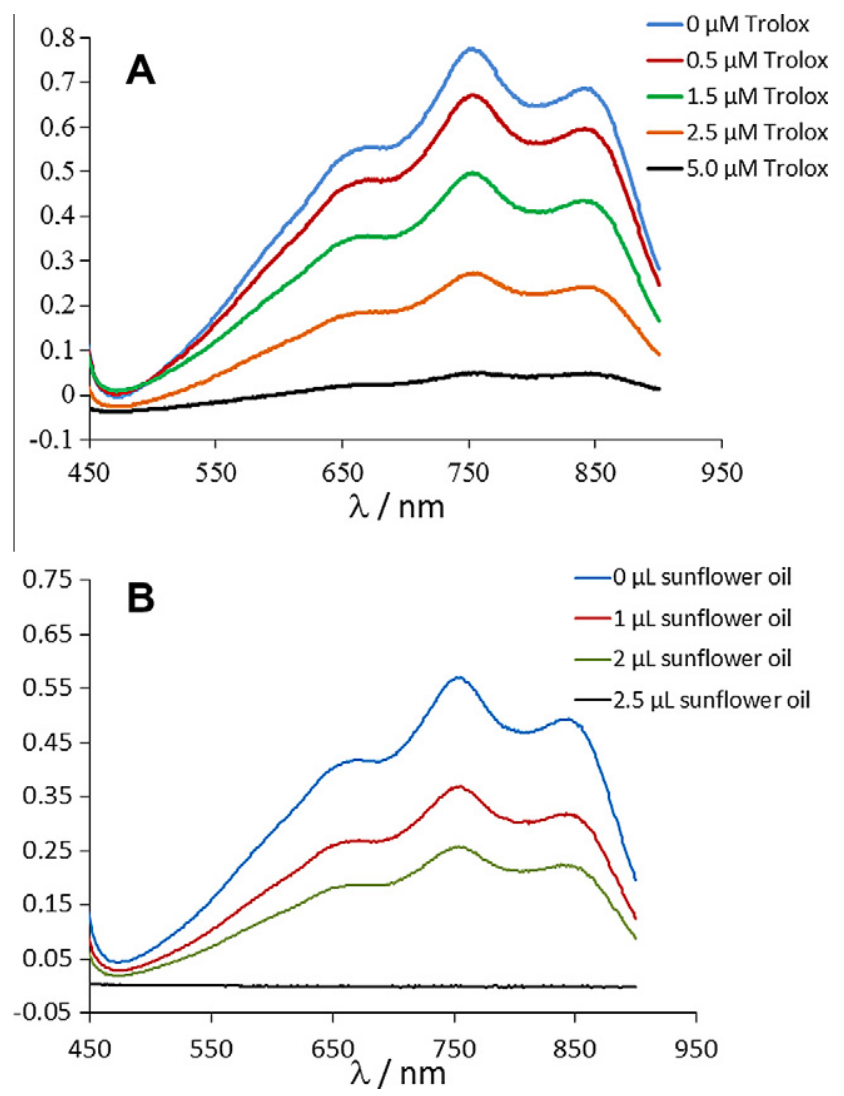

Fig. 4. Effect of the Trolox (A) and cold-pressed sunflower edible oils (B) to the UV-VIS spectra of ABTS.+ radical. Concentration of ABTS was $5 \mu \mathrm{mol} / \mathrm{L}$.

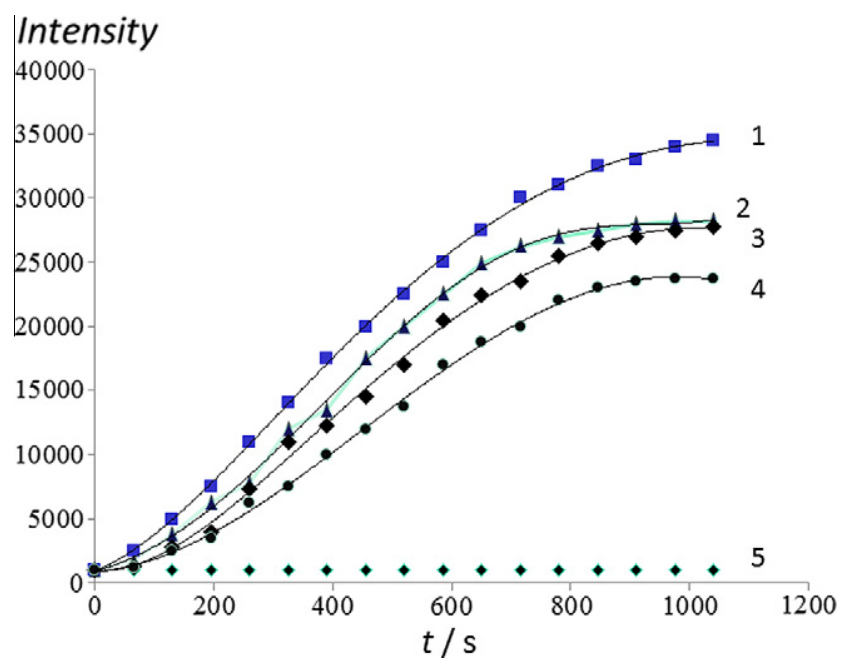

Fig. 5. Effect of the cold-pressed edible oils to the EPR signals of DMPO. The antioxidants present in the oils quench the superoxide radicals produced by macrophages, thus causing lowering of the signal intensity of the spin trapper compound DMPO. The curves are recorded in the absence of oil (1), and in presence of $1 \%(v / v)$ of oil-turnip (2), pumpkin (3) and sunflower (4) cold-pressed edible oils. Curve 5 is a controlling experiment that it is recorded in presence of excess of superoxide radical quencher, thus causing complete suppress of the EPR signal of DMPO.

\section{Conclusions}

In the current work we developed a rapid, cheap and simple voltammetric method to determine the total antioxidant capacity of cold-pressed edible oils. The method explores the ABTS assay as a redox mediator, and it relays to the so-called electrocatalytic regenerative mechanism of the $\mathrm{ABTS}^{+}$radical in a homogeneous redox reaction of its electrode product $\mathrm{ABTS}^{2+}$ with Trolox, or the antioxidants present in the cold-pressed edible oils. The method is applicable to all edible oils, and alternatively to other lipophilic liquid dietary products. The detection limit of the voltammetric method was estimated to be $0.5 \mathrm{mg} / \mathrm{L}$ of Trolox equivalent, being a slightly lower than the detection limit found by the UV-VIS spectrophotometric method. The proposed voltammetric method gives quite accurate information for the total redox capacity of the edible oils, and it can be explored for quick and routine determination of the total antioxidant capacity. Moreover, it can be used as a viable alternative to the UV-VIS methods for determination of total antioxidant capacity. Finally, the antioxidative activity of studied oils related to the superoxide anion radical created by macrophages was independently confirmed with EPR spectroscopy.

\section{Acknowledgments}

Authors gratefully acknowledge the help of Dr. Ivan Bogeski and Dr. Reinhard Kappl from the Faculty of Medicine Homburg, University of Saarland, Germany, for their help in performing EPR experiments. RG and VM acknowledge Alexander von Humboldt Foundation for the financial support via the bilateral GermanMacedonian project from the Research Group Linkage Programme 3.4-Fokoop-DEU/1128670. It is additionally acknowledged the support of DAADFoundation through multilateral project "International Masters and Postgraduate Programme in Materials Science and Catalysis" (MatCatNet) in the "Akademischer Neuaufbau Südosteuropa" programme. The authors also acknowledge the "Agrofila" company from Stip, Macedonia for providing us the cold-pressed edible oils.

\section{References}

Apak, R., Guclu, K., Demirata, B., Ozyurek, M., Celik, S. E., Bektasoglu, B., et al. (2007). Comparative evaluation of various total antioxidant capacity assays applied to phenolic compounds with the CUPRAC assay. Molecules, 12, 1496-1547.

Aruoma, I. O. (1998). Free radicals, oxidative stress and antioxidants in human health and disease. Journal of the American Oil Chemists Society, 75, 199-212.

Beardsell, D., Francis, J., \& Ridley, D. (2002). Health promoting constituents in plant derived edible oils. Journal of Food Lipids, 9, 1-34.

Belitz, H. D., \& Grosch, W. (1999). Phenolic compounds. In Food chemistry (pp. 764-775). Berlin: Springer.

Bogeski, I., Kappl, R., Kummerow, C., Gulaboski, R., Hoth, M., \& Niemeyer, B. A (2011). Redox regulation of calcium ion channels: Chemical and physiological aspects. Cell Calcium, 50, 407-423.

Buettner, G. R. (1993). The pecking order of free radicals and antioxidants, lipid peroxidation, $\alpha$-tocopherol and ascorbate. Archives of Biochemistry and Biophysics, 300, 535-543.

Cadenas, E., \& Davies, K. J. A. (2000). Mitochondrial free radical generation, oxidative stress and aging. Free Radical Biology E' Medicine, 29, 222-230.

Droge, W. (2002). Free radicals in the physiological control of cell function. Physical Review, 82, 47-95.

Geletii, Y. V., Balavoine, G. G. A., Efimov, O. N., \& Kulikova, V. S. (2002). The determination of total concentration and activity of antioxidants in foodstuffs. Russian Journal of Bioorganic Chemistry, 28, 501-514.

Gosser, K. D. (1994). Cyclic voltammetry: Simulation $\mathcal{E}$ analysis of reaction mechanisms. New York: Chapman \& Hall.

Gulaboski, R. (2008). In A. J. Bard, G. Inzelt, \& F. Scholz (Eds.). Electrochemical dictionary. Verlag: Springer.

Gunstone, F. D., \& Harwood, J. L. (2007). Occurrence and characterization of oils and fats. In F. D. Gunstone, J. L. Harwood, \& A. J. Dijkstra (Eds.), The lipid handbook (pp. 37-141). Boca Raton, FL: CRC Press.

Halliwell, G., \& Gutteridge, B. (2002). Free radicals in biology and medicine. Oxford University Press.

Manach, C., Scalbert, A., Morand, C., \& Jimenez, L. (2004). Polyphenols: Food sources and bioavailability. American Journal of Clinical Nutrition, 79, 727-747.

Mirceski, V., Komorsky-Lovric, S., \& Lovric, M. (2007). Square-wave voltammetry, theory and application. In F. Scholz (Ed.). Verlag: Springer.

Novak, I., Seruga, M., \& Komorsky-Lovric, S. (2009). Electrochemical characterization of epigallocatechin gallate using square-wave voltammetry. Electroanalysis, 21, 1019-1025. 
Novak, I., Seruga, M., \& Komorsky-Lovric, S. (2010). Characterisation of catechins in green and black teas using square-wave voltammetry and RP-HPLC-ECD. Food Chemistry, 122, 1283-1289.

O'Dea, J. J., Osteryoung, J., \& Osteryoung, R. A. (1981). Theory of square-wave voltammetry for kinetic systems. Analytical Chemistry, 53, 695-701.

Osteryoung, J., \& Osteryoung, R. A. (1985). Square-wave voltammetry. Analytical Chemistry, 57, 101A-110A.

Re, R., Pellegrini, N., Proteggente, A., Pannala, A., Yang, M., \& Rice-Evans, C. (1999). Antioxidant activity applying an improved ABTS radical cation decolorization assay. Free Radical Biology \& Medicine, 26, 1231-1237.

Stanner, S. A., Hughes, J., Kelly, C. N., \& Buttriss, J. (2004). A review of the epidemiological evidence for the antioxidant hypothesis. Public Health and Nutrition, 7, 407-422.
Stenken, S., \& Neta, P. (1982). One electron redox potentials of phenols, hydroxyand aminophenols and related compounds of biological interest. Journal of Physical Chemistry, 86, 3661-3667.

Visioli, F., Bogani, P., Grande, S., \& Galli, C. (2004). Olive oil and oxidative stress. Grasas y Aceites, 55, 66-75.

Yanishlieva-Maslarova, N. N., \& Heinonen, M. (2001). Sources of natural antioxidants. In J. Pokomy, N. Yanishlieva, \& M. Gordon (Eds.), Antioxidants in food (pp. 210-249). Boca Raton: CRC Press.

Yu, L. L., Zhou, K. K., \& Parry, J. (2005). Antioxidant properties of cold-pressed black caraway, carrot, cranberry, and hemp seed oils. Food Chemistry, 91, 723-729. 